\title{
Pathophysiological Complexity of Amiodarone- Induced Hypothyroidism (AlH) in patient With Congenital Heart Disease- Ebstein Anomaly: a case report
}

\section{Zvonimir Bosnic ( $\nabla$ zbosnic191@gmail.com )}

University of Osijek: Sveucilista Josipa Jurja Strossmayera u Osijeku https://orcid.org/0000-00024101-9782

\section{Domagoj Vucic}

Sveuciliste J J Strossmayera u Osijeku Studentski centar u Osijek

Nikica Marinic

Sveuciliste J J Strossmayera u Osijeku Studentski centar u Osijek

\section{Blazenka Saric}

Sveuciliste J J Strossmayera u Osijeku Studentski centar u Osijek

\section{Ljiljana Trtica Majnaric}

University of Osijek: Sveucilista Josipa Jurja Strossmayera u Osijeku

\section{Research Article}

Keywords: Amiodarone, Case report, Congeanital Heart Disease, Ebstein Anomaly, Hypothyroidism

Posted Date: April 5th, 2021

DOI: https://doi.org/10.21203/rs.3.rs-304220/v1

License: (c) (i) This work is licensed under a Creative Commons Attribution 4.0 International License.

Read Full License 


\section{Abstract}

Background: Amiodarone is a class III antiarrhythmic drug, used for the threatment of life threatening supraventricular and ventricular tachyarrhythmias and widely used in prevention of life threatening tachyarrhythmia in adults with congenital heart disease. Thyroid dysfunction is a potentially serious complication of amiodarone therapy, especially in older patients with acquired heart disease. Cause there is no published systematic study on amiodarone-associated hypothirodism in patients with congenital heart disease, we report the case of a patient with Ebstein anomaly, a rare congenital heart disorder, who developed hypothyroidism after prolonged amiodrone therapy. We report a possible pathophysiological link of amiodarone-induced hypothyroidism in a patient with rare congenital heart disease, that has not been reported in a significant number in the literature so far.

Case presentation: A female, 55-year-old patient with history of Ebstein anomaly (non operated), presented to a family medicine doctor with symptoms of progressive dyspnoea, fatigue and dysfagia for several months. Electrocardiography, echocardiography and chest X-ray confirmed presence of Ebstain anomaly. Laboratory results (including thyroid hormone values) and thyroid ultrasound were performed which confirmed the presence of hypothyroidism.

Conclusions: According to available data, there is no published systematic study on amiodaroneassociated hypothirodism in patients with congenital heart disease (large cohort studies). Pathophysiological complexity, however, could be due to the agent triggering autoimmune thyroid disease, so it is possible that amiodarone precipitated the onset of preexisting autoimmune disease. The value of regular thyroid function testing and measurement of thyroid antibodies should be considered in patients during amiodarone administration, especially in older patients with rare congenital heart disease.

\section{Background}

Amiodarone is an antiarrhythmic drug, class III, used for the treatment and prevention of life threatening supraventricular and ventricular tachyarrhythmias, atrial fibrillation (AF) and maintenance of sinus rhythm (1). It is a lipophilic molecule that accumulates in the myocardium, adipose tissue, skeletal muscles and thyroid gland. The effects of amiodarone on the thyroid tissue can be seen as early as a few weeks after starting treatment, while amiodarone and its metabolites demonstrate direct toxicity to cultured thyroid cells, or up to several months after its discontinuation (2). Long term use is associated with a number of side effects, including thyroid dysfunction (both hypo and hyperthyroidism), which is due to amiodarone's high iodine content and its direct toxic effect on the thyroid (3). The effects of amiodarone on thyroid function can be divided into those effects that are intrinsic properties of the drug and those that are due to iodine. Amiodarone-induced hyperthyroidism (AIT) is more common in iodinedeficient regions of the world, whereas amiodarone-induced hypothyroidism (AlH) is usually seen in iodine-sufficient areas. In the most European countries, the proportion of AIT (75\%) is higher compared to AlH (25\%), whereas in North America, where iodine intake is high, the proportion of AlH (66\%) is higher compared to that of AIT (34\%) (4). Amiodarone-induced thyrotoxicosis develops in $3 \%$ of amiodarone- 
treated patients in North America (5). Recent reviews of the literature noted that hypothyroidism occurs in $5-10 \%$ (6). AlH occurring especially in women with thyroid autoantibodies prior to treatment. Previous study in Netherlands showed an incidence between 6 and $6.9 \%$ for AlH (7). The relative high prevalence of thyroid autoantibodies, especially in women, the wide range of known triggers, and slow onset of autoimmune thyroid disease make this process difficult to associate with environmental agents, eventhough environmental exposures are subtle and can occur over a long period of time. Additionally, most individuals are exposed to multiple environmental toxins, and the combination of factors may also be significant for effects on the thyroid function. The presence of thyroid autoantiboides is s known risk factor for the development of autoimmune thyroid disease (8). Amiodarone is widely used in adults with congenital heart diseases (CHD) for decades. Previous studies suggested that low-dose amiodarone ( $\leq$ $200 \mathrm{mg} /$ day) is useful and effective for decreasing the frequency of tachyarrhythmia in patients with $\mathrm{CHD}$ and has a low incidence of side effects (9).

Ebstein anomaly is a rare disease, accounting for $<1 \%$ of all cases of CHD $(0.3-0.6 \%)$, characterized by tricuspid valve hypoplasia with apically displaced septal and posterior leaflets, which may induce severe tricuspid regurgitation and dilation of the "atrialized" portion of the right ventricle (10). Malformation in Ebstein's anomaly may range from only minimal displacement of the septal and posterior leaflets to an imperforate membrane or muscular shelf between the inlet and trabecular zones of the right ventricle. Hemodynamic abnormalities are dependent on the severity of the lesion. In mild Ebstein anomaly, tricuspid valve function is close to normal. In moderate to severe forms, with each atrial contraction the

blood is propelled into the atrialized right ventricule. With ventricular contraction, blood is forced back into the right atrium (11). Prevoius studies noted that only $5 \%$ of patients survive beyond the fifth decade (12). Patients usually present with symptoms associated with heart failure due to the dilated and atrialized right ventricle compressing the left ventricle and, additionally, reducing preload for the left heart (13). The therapeutic approach of Ebstein anomaly in elderly is very discutable, because the operative indication of asymptomatic Ebstein's anomaly in adult patients has not been clearly defined (14). Eventhough operative repair of Ebstein's anomaly is indicated usually during younger age, medical management may be used to manage some of the symptoms of heart failure and arrhythmias, especially in NYHA classes I and II. Surgery is indicated when the patient's symptoms progress to NYHA class III or IV, increasing cyanosis becomes evident, or if paradoxical embolism occurs (15). A large cohort Study from Mayo clinic demonstrated good benefits from surgery, and better postoperative outcomes in NYHA functional classes I and II (in $40 \%$ of patients) (16).

\section{Case Presentation}

A female, 55-year-old patient, married, working as a secretary, with history of Ebstein anomaly (non operated), presented to a family medicine doctor with symptoms of progressive dyspnoea, weakness and dysfagia for several months. Patient's medical history included hypertension, dyslipidemia, cessation of smoking and had no family or personal history of thyroid disease. She has been treated with Perindopril of $2 \mathrm{mg}$ for hypertension control and Rosuvastatin $20 \mathrm{mg}$ for dyslipidemia. Her blood pressure was 100/70 mmHg, pulse rate 115/min, and pulsus paradoxus was present. Cyanosis (peripheral oxygen 
saturation 96\%), clubbing and massive peripheal edema were absent. Auscultation revealed muffled heart sounds. Laboratory results showed high sedimentation rate $(38 \mathrm{~mm} / \mathrm{hr})$, elevated thyroid-stimulating hormone (25 IU/L), elevated thyroglobulin $(250 \mathrm{U} / \mathrm{I})$ and thyroid peroxidase antibodies (300 U/I), and normal values of free triiodothyronine (fT3) and free thyroxine (fT4). Electrocardiography revealed low voltage complex with sinus tachycarida (frequency $120 / \mathrm{min}$ ) and complete right bundle branch block. Chest X-ray (posteroanterior view) showed cardiomegaly with globular heart, small aortic root and decreased pulmonary vasculature. Echocardiography verified the presence of Ebstein anomaly, involving an apical-ward shifting tricuspid valve, severe tricuspid regurgitation, patent foramen ovale (PFO) with bidirectional shunts, and a dilated right ventricle and left atrium. Left ventricle could not be delineated precisely. Also, it revealed severe pulmonary hypertension. Thyroid ulrasound was performed and showed overactive thyroid tissue, with homogenous node in the right lobe. She had been treated with amiodarone $400 \mathrm{mg}$ per os for the last 10 years for the purpose of maintaining sinus rhythm due to paroxysmal sinus tachycardia. Upon initiation of amiodarone therapy (indicated by a cardiologist), free thyroxine and thyroid-stimulating hormone were routinely measured at 6-month intervals for the first two years of therapy. After that, the patient no longer reported for check-ups to the cardiologist or to her family medicine doctor.

The patient was examined by an endocrinologist who recommended the introduction of levothyroxine at a dose of $25 \mu \mathrm{g}$ per day and increasing the dose to $50 \mu \mathrm{g}$ per day after the first week of therapy. Also, she was examined by an otolaryngologist, who has suggested operation of homogenous node in right thyroid lobe. The anesthesiologist, due to numerous comorbidities and increased perioperative risk, did not give permission to perform general anesthesia. The patient was referred again to a cardiologist who performed an echocardiography which verified a large pericardial effusion (without threatening tamponade), right heart failure, and severe pulmonary hypertension. Therefore, amiodarone was excluded and bisoprolol $5 \mathrm{mg}$ was initiated.

\section{Discussion}

The symptoms of AlH are identical to that of primary hypothyroidism and may develop as soon as 2 weeks or as late as 39 months after the initiation of amiodarone therapy (17). Because AlH is an early event, occurring especially in women with thyroid autoantibodies prior to treatment, patients are at greatest risk for developing autoimmune thyroid disease, espeacially those with previously present thyroid autoantibodies. Eventhough there has been no clear consensus regarding the frequency of screening for amiodarone-induced thyroid dysfunction in patients on chronic amiodarone treatment, previous studies suggested a complete thyroid examination before initiating therapy with amiodarone, along with baseline measurements of thyroid hormones and antibody values (18). The same can help to identify patients who may be predisposed of developing thyroid dysfunction while on amiodarone (Fig. 1). The etiology of most functional disorders of the thyroid is autoimmunity. The onset of autoimmune thyroid disease is thought to be due to environmental exposures or triggers. At baseline, those who developed a thyroid event had a higher thyroid-stimulating hormone, higher thyroid peroxidase antibody levels, and more blood relatives with Hashimoto's disease (19). 
Medications associated with the greatest risk for developing autoimmune thyroid disease include amiodarone, lithium, interferon $\mathrm{a}$, interleukin 2 , campath- $1 \mathrm{H}$, and highly active anti-retroviral therapy. Thyroid function testing and measurement of thyroid peroxidase antibodies should be considered in patients before beginning these medications (20). Also, AlH may develop either in apparently normal thyroid glands or in glands with preexisting, clinically silent abnormalities (21). Still, there is no published systematic study on amiodarone-associated thyroid dysfunction in patients with CHD, who constitute a significant population.

The similarity between the underlying thyroid disease and the cause of the disease itself support the complex pathophysiological thinking, and may represent the basis to refine the diagnostic criteria and to improve the therapeutic outcomes of this challenging clinical situation. The quantitative risk of developing overt autoimmune thyroid disease (AITD) can be estimated by the Thyroid Events Amsterdam (THEA) score (22).

While thyroid dysfunction is relatively common in amiodarone therapy, all patients should have free thyroxine and thyroid-stimulating hormone levels measured before starting therapy, at three to four-month intervals during treatment, and for at least one year after the amiodarone is discontinued. Further prospective studies are needed to examine the mechanism of amiodarone-associated thyroid dysfunction and to further evaluate pathophysiologial associtation between AlH and autoimmunity. In high risk patients for developing AIT or AlH, dronedarone is devoid of iodine and with fewer adverse effects, therefore it may be used in treatment (23).

\section{Conclusion}

According to available data, there is no published systematic study on amiodarone-induced hypothirodism in patients with congenital heart disease (large cohort studies). Pathophysiological complexity, however, could be due to the agent triggering autoimmune thyroid disease, so it is possible that amiodarone precipitated the onset of preexisting autoimmune disease. The value of regular thyroid function testing and measurement of thyroid peroxidase antibodies should be considered in patients during amiodarone administration, especially in older patients with rare congenital heart disease.

\section{Declarations}

\section{Funding:}

no funding was received.

\section{Authors' contributions:}

ZB and LJTM were responsible for conceptualization, design of the study and formal analysis. DV, NM, BS performed the literature review, collected data. In addition, they were responsible for data validation and funding acquisition. ZB and LJTM provided administration. LJTM supervised and edited the 
manuscript. ZB wrote the manuscript. All authors have read and agreed on the published version of the manuscript

\section{Acknowledgements:}

none.

Zvonimir Bosnić, MD Department of Internal Medicine, Family Medicine and the History of Medicine, Faculty of Medicine, Josip Juraj Strossmayer University of Osijek

\section{References}

1. Goldschlager N, Epstein AE, Naccarelli G, et al. (2000) Practical guidelines for clinicians who treat patients with amiodarone. Practice Guidelines Subcommittee, North American Society of Pacing and Electrophysiology. Arch Intern Med 160:1741-8.

2. Cardenas GA, Cabral JM, Leslie CA (2003) Amiodarone-induced thyrotoxicosis: Diagnostic and therapeutic strategies. Cleve Clin J Med 70:624-31.

3. Tsang W, Houlden RL (2009) Amiodarone-induced thyrotoxicosis: a review. Can J Cardiol 25(7):421424.

4. Tanda ML, Piantanida E, Lai A, Liparulo L, Sassi L, Bogazzi F et al Diagnosis and management of amiodarone-induced thyrotoxicosis: similarities and differences between North American and European thyroidologists (2008) Clinical Endocrinology, 69(5):812-8.

5. Bouvy ML, Heerdink ER, Hoes AW, Leufkens HG (2002) Amiodarone-induced thyroid dysfunction associated with cumulative dose. Pharmacoepidemiol Drug Saf 11:601.

6. Cohen-Lehman J, DahI P, Danzi S, Klein I (2010) Effects of amiodarone therapy on thyroid function. Nat Rev Endocrinol Jan 6(1):34-41.

7. Trip MD, Wiersinga W and Plomp TA (1991) Incidence, predictability, and pathogenesis of amiodarone-induced thyrotoxicosis and hypothyroidism. American Journal of Medicine, vol 91, pp 507-511.

8. Brent GA (2010) Environmental exposures and autoimmune thyroid disease. Thyroid 20(7):755-761.

9. Iwasawa S, Uyeda T, Saito M, et al. (2018) Efficacy and Safety of Low-Dose Amiodarone Therapy for Tachyarrhythmia in Congenital Heart Disease. Pediatr Cardiol 39(5):1016-1022.

10. Sharma N, Lalnunnem TJ, Nandwani M, Santa SA, Synrang BW (2018) Ebstein Anomaly with Pregnancy: A Rare Case. J Reprod Infertil 19(2):119-122.

11. Voges I, Al-Mallah MH, Scognamiglio G, Di Salvo G (2018) Right Heart-Pulmonary Circulation Unit in Congenital Heart Diseases. Heart Fail Clin 14(3):283-295.

12. D'Andrea A, Scognamiglio G, Giordano F, Cuomo S, Russo MG, Rinaldi G et al. (2011) An atypical assessment of Ebstein's anomaly in an 86-year-old man. Monaldi Arch Chest Dis 76:104-105. 
13. Nakayama T, Asano M, Matsumoto K, et al. (2007) Reconstruction of the right heart in an elderly woman with Ebstein's anomaly and severe right heart failure. Ann Thorac Surg 84: 1745-6.

14. Kawase I, Ozaki S, Kawada M (2008) Repair of Ebstein's anomaly in an elderly patient; report of a case. Kyobu Geka 61:887-890.

15. Brown M, Dearani J (2011) Ebstein anomaly, Diagnosis and Management of Adult Congenital Heart Disease, 2ed ed, Atlanta, Elsevier Sunders pp 288-294.

16. Brown ML, Dearani JA, Danielson GK, et al. (2008) Functional status after operation for Ebstein anomaly: the Mayo Clinic experience. J Am Coll Cardiol 52:460-6.

17. Nademanee K, Piwonka RW, Singh BN, Hershman JM (1989) Prog Cardiovasc Dis 31(6):427-37.

18. Basaria S, Cooper DS (2005) Amiodarone and the thyroid. Am J Med 118: 706-714.

19. Strieder TGA, Tijssen JGP, Wenzel BE, Endert E, Wiersinga WM (2008) Prediction of progression to overt hypothyroidism or hyperthyroidism in female relatives of patients with autoimmune thyroid disease using the thyroid events Amsterdam (THEA) score. Arch Intern Med. 168:1657-1663.

20. Burek CL, Talor MV (2009) Environmental triggers of autoimmune thyroiditis. J Autoimmun. 33:183189.

21. Ursella S, Testa A, Mazzone M, Gentiloni Silveri N (2006) Amiodarone-induced thyroid dysfunction in clinical practice. Eur Rev Med Pharmacol Sci 10(5):269-278.

22. Strieder TG, Tijssen JG, Wenzel BE, Endert E, Wiersinga WM (2008) Prediction of progression to overt hypothyroidism or hyperthyroidism in female relatives of patients with autoimmune thyroid disease using the Thyroid Events Amsterdam (THEA) score. Archives of Internal Medicine 168(15):1657-63.

23. Jukic T, Punda M, Franceschi M, Stanicic J, Granic R, Kusić Z (2015) Amiodarone and the thyroid function. Lijec Vjesn 137(5-6):181-188.

\section{Figures}

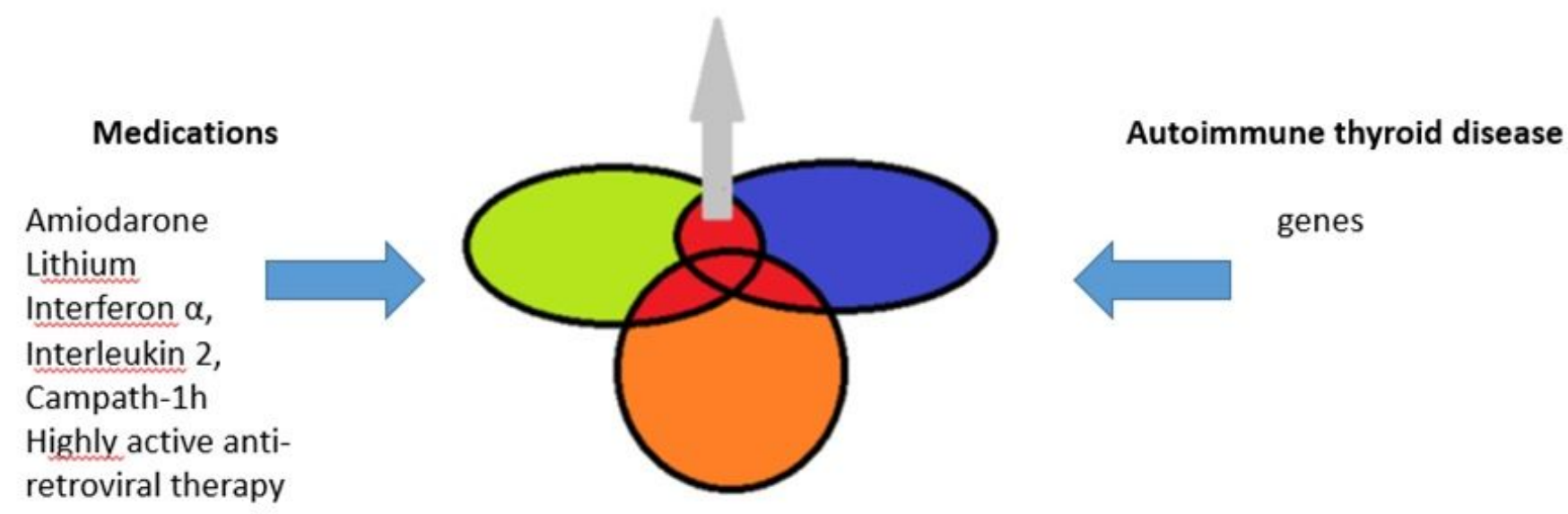


Figure 1

Patophysiological complexity of AlH and autoimmune thyroid disease

\section{Supplementary Files}

This is a list of supplementary files associated with this preprint. Click to download.

- CAREchecklistEnglish2013new.pdf 